\title{
Ultrasensitive and rapid count of Escherichia coli using magnetic nanoparticle probe under dark-field microscope
}

\author{
Haixu Xu' ${ }^{1}$, Fang Tang ${ }^{2}$, Jianjun Dai ${ }^{2}$, Chengming Wang ${ }^{3}$ and Xin Zhou ${ }^{1 *}$
}

\begin{abstract}
Background: Escherichia coli (E. coli) is one of the best-known zoonotic bacterial species, which pathogenic strain can cause infections in humans and animals. However, existing technologies or methods are deficient for quickly on-site identifying infection of E. coli before they breakout. Herein, we present an ultrasensitive and on-site method for counting E. coli using magnetic nanoparticle (MNP) probe under a dark-field in $30 \mathrm{~min}$.

Results: The antibodies functionalized MNP, binding to $E$. coli to form a golden ring-like structure under a dark-field microscope, allowing for counting E. coli. This method via counting MNP-conjugated E. coli under dark-field microscope demonstrated the sensitivity of $6 \mathrm{CFU} / \mu \mathrm{L}$ for $E$. coli detection. Importantly, due to the advantages such as time-saving (only $30 \mathrm{~min}$ ) and almost free of instrument (only require a portable microscope), our MNP-labeled dark-field counting strategy has the potential of being a universal tool for on-site quantifying a variety of pathogens with size ranges from a few hundreds of nanometers to a few micrometers.
\end{abstract}

Conclusion: In summary, the MNP-labeled dark-field counting strategy is a rapid, simple, sensitive as well as low-cost assay strategy, which has the potential of being a universal tool for on-site quantification of micrometer-size pathogens like E. coli.

Keywords: Rapid enumeration, Escherichia coli, Magnetic nanoparticle, Dark-field microscope

\section{Background}

E. coli is a rod-like bacterium and the genus Escherichia contains mostly motile Gram-negative bacilli in the family of Enterobacteriaceae. Most of the E. coli strains are not harmful to humans but some strains possess pathogenic virulence, which increase the ability to adapt new niches and allow them to cause broad spectrum of diseases [1]. In recent years, the foodborne diseases emerged as major concern in public [2]. Therefore, rapid, inexpensive and sensitive methods are required to detect the E. coli infection.

During last decades, several molecular and immunological methods have been developed to detect E. coli.

\footnotetext{
* Correspondence: zhou_xin@126.com

${ }^{1}$ Institute of Comparative Medicine, Jiangsu Co-innovation Center for Prevention and Control of Important Animal Infectious Diseases and Zoonoses, Joint International Research Laboratory of Agriculture and Agri-Product Safety, the Ministry of Education of China, Yangzhou University, Yangzhou 225009, China

Full list of author information is available at the end of the article
}

Such as polymerase chain reaction (PCR), real-time PCR, multiplexed PCR, loop-mediated isothermal amplification, Pulsed-Field Gel Electrophoresis, Gene-chip, next generation sequencing, enzyme linked immunosorbent assay (ELISA) and immune chromatography. Despite the fact of these approaches are powerful, they have drawbacks such as laboriousness, high-cost, complexity, and requirement of expensive instruments or reagents. Most importantly, they are not able for on-site assay [3-11]. Recently, the biosensor technology plays an important role in the detection of pathogenic bacteria because they have great potential to meet the practical need of rapid, sensitive, easy-to-use, and low-cost [12, 13]. Biosensor technology implemented with the use of nanoparticles (NPs) tags and also other nanomaterials offers benefits compared with traditional methods in terms of time, sensitivity and simplicity [14-17].

In this study, we demonstrated a quick and sensitive counting of $E$. coli at low concentrations without bacteria pre-enrichment by employing a MNP probe combined 
with dark-field microscope. The schematic diagram of our MNP-labeled dark-field counting strategy is shown in Fig. 1.

\section{Results}

\section{Validation of MNP probes}

The electrophoresis result clearly showed the presence of two bands ( $\mathrm{a} \sim 50 \mathrm{kDa}$ band of antibody heavy chain and $\mathrm{a} \sim 20 \mathrm{kDa}$ band of antibody light chain) in MNP probes sample (Fig. 2, lane 3), indicating successful bio-functionalization of MNP probes.

\section{Detection of $E$. coli cultured in laboratory with our counting strategy}

The results show that each bacteria was encircled with MNP probes to form dim bacilliform structures under light field (Fig. 3c) and bright gold ring structure under dark-field microscope (Fig. 3d), which was also confirmed by TEM (Fig. 3f). On the contrary, E. coli mixed with MNP without anti-E. coli antibodies were observed under a bright and dark-field microscope. E. coli were dim and indistinct under bright field (Fig. 3a) and were completely invisible under dark field (Fig. 3b) due to no recognition between $E$. coli and MNP particles, which was verified by TEM (Fig. 3e). The Fig. 3g clearly showed that Salmonella bacteria did not bind to MNP probes, which suggests that our MNP probes has a specific affinity to target species.

Determination of limit of detection of our counting assay Figures $4 \mathrm{a}\left(10^{2} \mathrm{CFU} / \mu \mathrm{L}\right)$ and $4 \mathrm{~b}(10 \mathrm{CFU} / \mu \mathrm{L})$ show that many monodisperse golden ring-like structures can be counted under dark-field. Even in Fig. 4c (1 CFU/ $\mu \mathrm{L}$ of

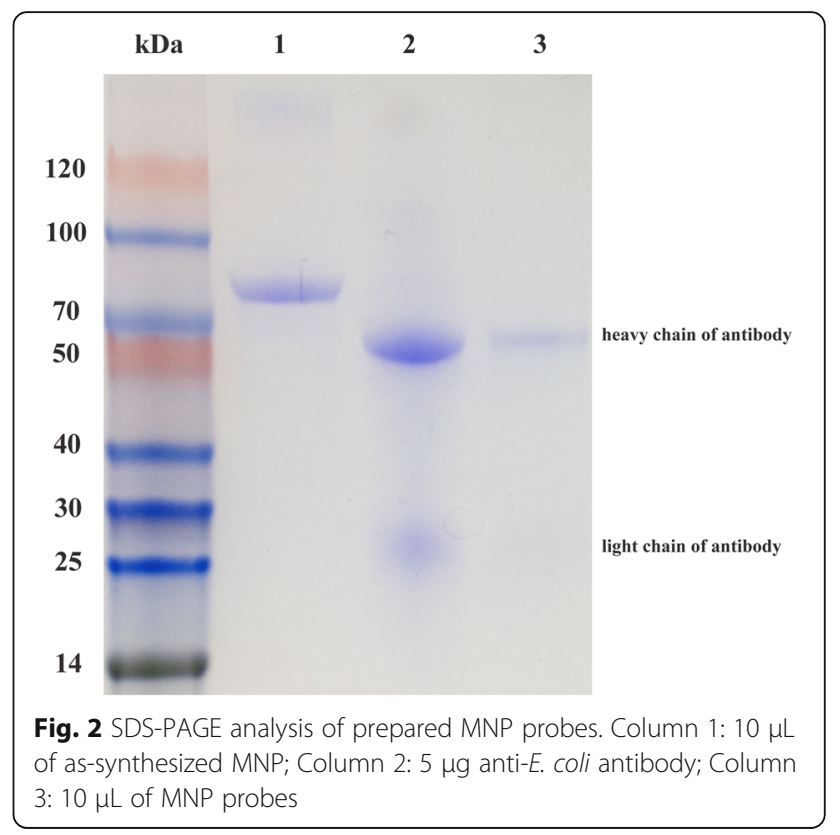

E. coli sample), we could also occasionally find one or two bright golden ring structure in a certain field of view. The limit of detection is defined as three times the signal-to-noise ratio, which is calculated by counting the number of golden ring-like E. coli found in 10 random fields of view of background experiment (naked MNP mixed with E. coli). Because $10 \mu \mathrm{L}$ of sample solution covers the area of 200 field of views (each view area equal to $100 \mu^{2}$ ) and the background experiments showed that one dim ring-like structure could be occasionally found in 10 random field of views, LOD of our counting method could be defined as $6 \mathrm{CFU} / \mu \mathrm{L}$. The

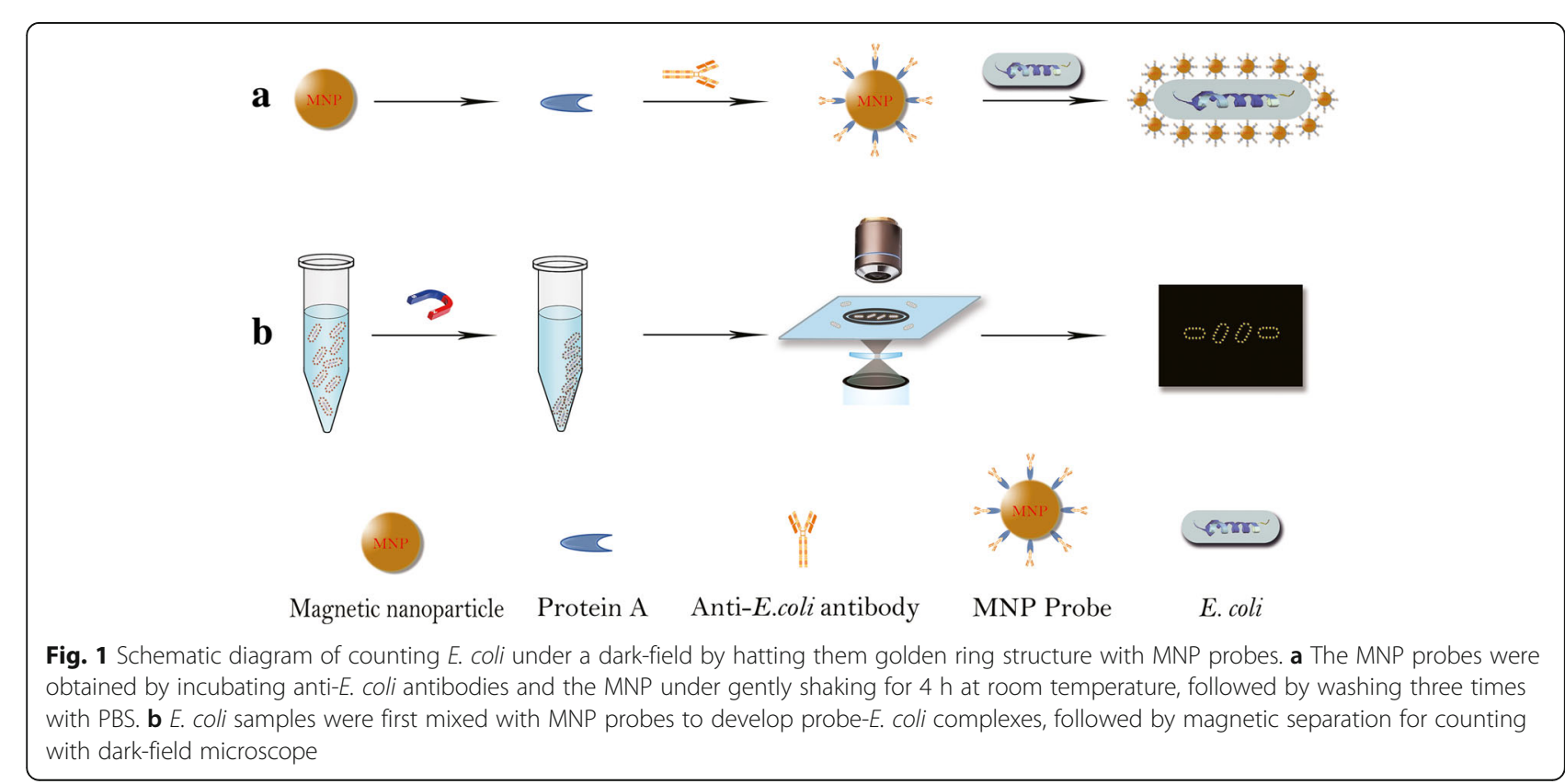



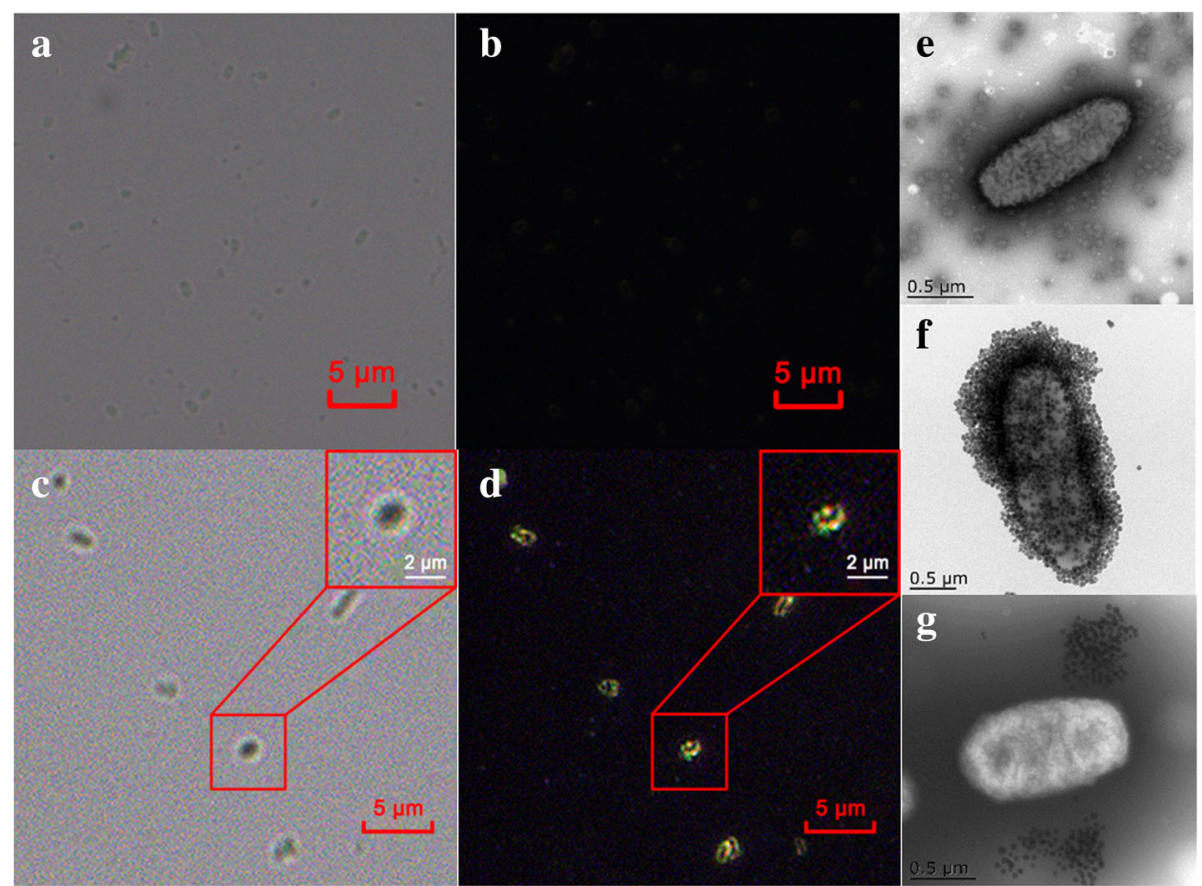

f

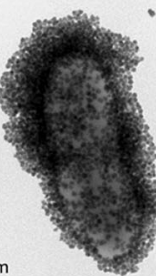

$\underline{0.5 \mu \mathrm{m}}$

g

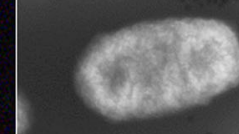

Fig. 3 Microscope images of $E$. coli at different conditions. a $E$. coli without MNP probes under a bright field; $\mathbf{b} E$. coli without MNP probes under a dark-field; $\mathbf{c} E$. coli mixed with MNP probes under a bright field; $\mathbf{d} E$. coli mixed with MNP probes under a dark-field; e Transmission Electronic Microscope (TEM) image of E. coli mixed with naked MNPs. $\mathbf{f}$ TEM image of . coli with MNP probes. $\mathbf{g}$ Salmonella mixed with MNP probes; Red box in the upper right corner of $d$ and $e$ is the enlargement of the selected area, respectively
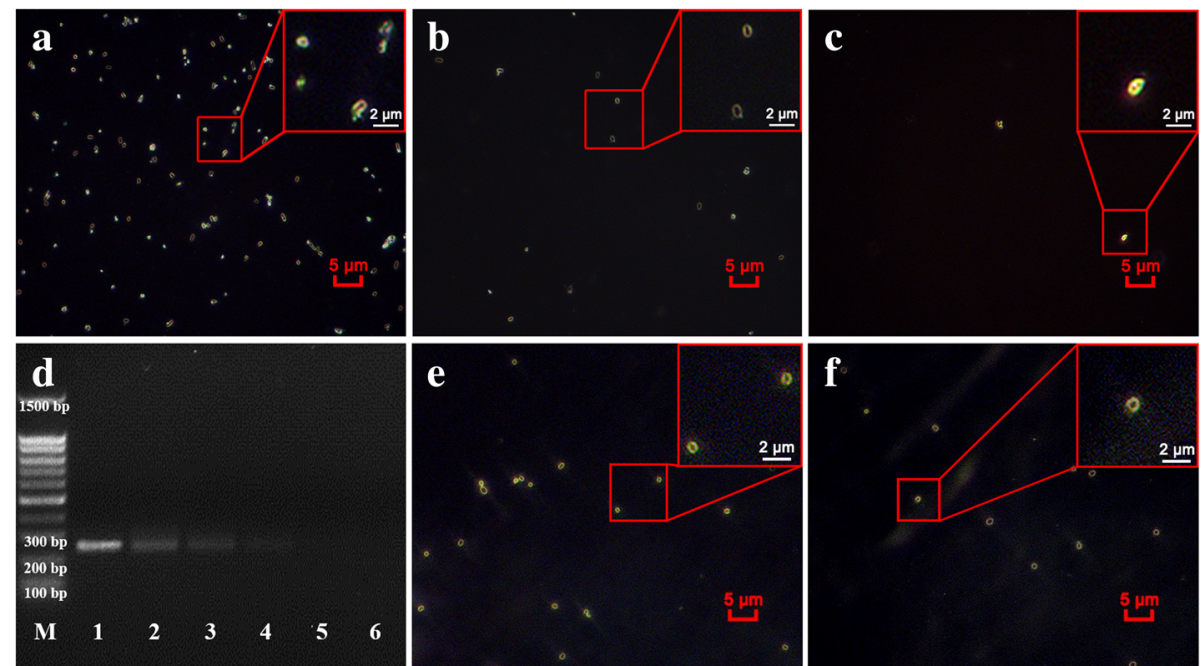

Fig. 4 Sensitivity analysis of E.coli at different dilution concentrations and count of two real samples by our MNP-based strategy. a $10^{3}$ dilution of E. coli stock solution (equal to $10^{2} \mathrm{CFU} / \mu \mathrm{L}$ ) captured by MNP probe; $\mathbf{b} 10^{4}$ dilution of E. coli stock solution (equal to $10 \mathrm{CFU} / \mu \mathrm{L}$ ) captured by MNP probe; $\mathbf{c} 10^{5}$ dilution of $E$. coli stock solution (equal to 1 CFU/ML) captured by MNP probe. $\mathbf{d}$ PCR analysis of E.coli at different dilution concentrations. M: DNA Marker; Line 1: E. coli stock solution; Line 2-6: $10^{1}, 10^{2}, 10^{3}, 10^{4}$ and $10^{5}$ dilution of E. coli stock solution, respectively; Red box in the upper right corner of $\mathbf{a}, \mathbf{b}$ and $\mathbf{c}$ is the enlargement of the selected area, respectively. e A representative dark-field image of $E$. coli in ten-fold concentration dilute soup sample captured by MNP probes; $\mathbf{f}$ A representative dark-field image of $E$. coli in ten-fold concentration rice sample captured by MNP probes 
maximum quantity of $E$. coli in single field of view can be used to clearly count is approximated to $300 \mathrm{CFU}$, the suitable concentration range by our MNP-based counting method is from 6 to $6000 \mathrm{CFU} / \mu \mathrm{L}$. The results show the LOD of PCR in this study is $100 \mathrm{CFU} / \mu \mathrm{L}$ (Fig. $4 \mathrm{~d}$, line 4) because the band from $10 \mathrm{CFU} / \mu \mathrm{L}$ sample is invisible to the naked eye. These results indicate that the theoretical sensitivity of our counting strategy is 15 times more sensitive than that of PCR technique. Moreover, it is worth to mention that, strictly speaking, no false positive happened using our MNP-based dark-field microscopy counting method because no bright gold ring structures formation in the absence of target pathogens.

\section{Detection of real samples with MNP-labeled dark-field counting strategy}

Two food samples that were exposed to the air for $24 \mathrm{~h}$ in our lab were quantified with our MNP-labeled dark-field counting method. As shown in the Table 1, $163 \pm 16 \mathrm{CFU} / 10 \mu \mathrm{L}$ from soup sample and $126 \pm$ $14 \mathrm{CFU} / 10 \mu \mathrm{L}$ from rice sample could be obtained by counting the clones in petri dishes (The raw counting images were shown in Additional file 1: Figures. S1 and S2). Using our counting method, $142 \pm 14 \mathrm{CFU} / 10 \mu \mathrm{L}$ and $112 \pm 8 \mathrm{CFU} / 10 \mu \mathrm{L}$ could be counted, respectively (the raw dark-field images by our counting strategy were shown in Additional file 1: Table S1). The high coincidence rate $(\sim 87 \%)$ compared to the clone counting method and efficient detection time of 30 min suggest that our strategy will be a more advantageous method of enumeration of $E$. coli in real samples than the traditional method that normally takes $10 \mathrm{~h}$ for analysis. Figure $4 \mathrm{e}$ and Fig. 4f are the representative dark-field images of MNP-E. coli from the ten-fold concentration dilute soup and rice, respectively (Additional file 1: Figures. S3 to S8).

\section{Discussion}

Since the quantity of $E$. coli is used as a potential indicator for the presence of other pathogens in many samples [18], the number of $E$. coli is essential for evaluating the extent of enteric disease by pathogenic bacteria such as enterohemorrhagic strains of E. coli $[19,20]$ that contaminates food

Table 1 Detection of real samples by traditional colony counting and MNP-labeled dark-field counting strategy

\begin{tabular}{lll}
\hline Samples & $\begin{array}{l}\text { Colony counting method } \\
\text { (CFU of } 10 \mu \mathrm{L} \text { of sample) }\end{array}$ & $\begin{array}{l}\text { Our counting strategy } \\
\text { (CFU of } 10 \mu \mathrm{L} \text { of sample) }\end{array}$ \\
\hline Dilute soup & $163 \pm 16$ & $142 \pm 14$ \\
Rice & $126 \pm 14$ & $112 \pm 8$
\end{tabular}

Statistical analysis: The experimental counting results are reported as means \pm SE of triplicate independent experiments. Ten fields of view were counted for each sample. Data were analyzed using the SPSS (Statistical Package for the Social Sciences) software (Version 13.0; SPSS, Inc., Chicago, IL) or water [20,21]. Conventional identification methods for bacteria involves several steps: selective culture, Gram staining, as well as biochemical and/or serological tests, which are still considered as gold standard for E. coli detection [22]. However, the conventional assay is labor-intensive and often time-consuming and strenuous to obtain a confirmed result. Theoretically, the sensitivity of our MNP-labeled dark-field counting strategy can reach $1 \mathrm{CFU}$ in $10 \mu \mathrm{L}$ of sample solution because the structure of non-specific adsorption formation is far from the bright gold ring. However, considering the convenience of practical assay, the LOD of our counting method can be determined approximate to $6 \mathrm{CFU} / \mu \mathrm{L}$. And the suitable concentration range by our MNP-based counting method is from 6 to $6000 \mathrm{CFU} / \mu \mathrm{L}$. The wide range of detection (6 to $6000 \mathrm{CFU} / \mu \mathrm{L}$ ) can cover a variety of $E$. coli samples even without concentration or dilution; therefore, our MNP-labeled dark-field counting strategy is an efficient technique for counting the $E$. coli from different samples.

In this study, a rapid, reliable and effective assay has been demonstrated for the detection of $E$. coli in samples with different concentrations. The sensitivity of the MNP-based counting method was thoroughly investigated and compared to the conventional PCR assay. The data showed that LOD of our counting method is down to $6 \mathrm{CFU} / \mu \mathrm{L}$, which greatly exceeds the PCR assay (the LOD of PCR assay performed in this study is $100 \mathrm{CFU} / \mu \mathrm{L})$. Owing to the advantages such as time-saving $(\sim 30 \mathrm{~min})$ and almost free of instrument (only the requirement of a portable microscope), MNP-labeled dark-field counting strategy has the potential of being a universal platform for on-site quantifying a variety of pathogens in all sizes ranging from hundreds of nanometers to micrometers. The MNP-based counting method potentially allows for on-site use in the monitoring of water quality, food safety and environmental parameters.

\section{Conclusion}

In summary, a rapid, simple, sensitive as well as low-cost assay has been developed for on-site enumeration of micrometer-size pathogens like E. coli.

\section{Methods}

\section{Bacterial culture}

E. coli $\mathrm{O} 78$ used in this study was a gift from Dr. Fang Tang (College of veterinary medicine, Nanjing Agricultural University). The bacteria were cultured in Luria Bertani (LB) medium and kept shaking at $220 \mathrm{rpm}$ at $37{ }^{\circ} \mathrm{C}$ over night. Then the cells were harvested and washed for several times with $10 \mathrm{mM}$ PBS solution $(\mathrm{pH}=7.4)$. Optical density at $600 \mathrm{~nm}\left(\mathrm{OD}_{600}\right)$ was measured and adjusted to around 0.60 , corresponding to bacteria concentration of $10^{8} \mathrm{CFU} / \mathrm{mL}$. 


\section{Preparation of MNP probes}

To demonstrate the proof-of-concept above, the MNP probes were prepared as follows: 1) Protein A functionalized MNPs (Creative Diagnostics, USA) at diameter of $\sim 50 \mathrm{~nm}$ were incubated with anti-E. coli polyclonal antibody $(5 \mu \mathrm{g} / \mu \mathrm{L})(\mathrm{PA} 1-7213$, Thermo Fisher, USA) for $4 \mathrm{~h}$ at room temperature. 2) The MNP probes were washed three times with PBS by magnetic stand to remove the unattached E. coli antibodies and then were stored at $4{ }^{\circ} \mathrm{C}$ until use. 3) To investigate the successful modification of antibody, MNP probes were assayed using the sodium dodecyl sulfate-polyacrylamide gel electrophoresis (SDS-PAGE).

\section{Detection of E. coli with MNP-labeled dark-field counting strategy}

With the achievement of prepared MNP probes, we next examined the feasibility of counting $E$. coli under dark-field microscope. The counting assay solution containing $50 \mu \mathrm{L}$ of MNP probes $\left(\sim 8 \times 10^{11}\right.$ particles $), 10 \mu \mathrm{L}$ of E. coli $\left(\sim 1.0 \times 10^{6} \mathrm{CFU}\right)$ and $140 \mu \mathrm{L}$ of PBS (pH 7.4) was gently mixed for $25 \mathrm{~min}$ at room temperature, and then immediately separated by magnetic stand. The resulting solution was further washed three times with PBS and subjected to dark-field microscopy and transmission electron microscopy (TEM, Tecnai 12, Philips, Holland). A Salmonella strain (BNCC103307, purchased from ATCC) was employed as a control to investigate the specificity of MNP probes.

\section{Investigation of sensitivity of MNP-labeled dark-field counting strategy}

In addition, the sensitivity of the proposed method was subsequently investigated. A serial of $E$. coli samples cultured in LB medium at different concentrations were employed to investigate the limit of detection (LOD) using our MNP-based dark-field microscopy counting method. Briefly, the E. coli stock solution was diluted with PBS buffer into five samples at different concentration from $10^{0}$ to $10^{4} \mathrm{CFU} / \mu \mathrm{L}$. $10 \mu \mathrm{L}$ of $E$. coli sample solution was mixed with $50 \mu \mathrm{L}$ of MNP probes and $140 \mu \mathrm{L}$ of PBS $(\mathrm{pH}=7.4)$ for $25 \mathrm{~min}$, and then separated by magnetic stand, finally subjected to dark-field microscopy. Meanwhile, PCR assay was employed as a compared method to evaluate the sensitivity of our counting strategy. To this end, a pair of primers (forward primer: 5'-TAGGTATTCCTGTTGCGGAGTATAT-3'; reverse primer: 5'-TACTATACATCAAACCCTCAGCATT-3') were designed to amplify a fragment of specific $E$. coli gene (6-phosphoguuconate dehydrogenase). PCR were performed according to standard procedure and $2 \mu \mathrm{L}$ of each of $E$. coli samples at different concentration was used as template in each PCR reaction.

\section{Detection of real samples with MNP-labeled dark-field counting strategy}

Furthermore, two real samples, one of which is a dilute meat soup and the other is a rice exposed to air for two days, were employed to demonstrated the availability of our MNP-labeled dark-field counting strategy. Firstly, two samples were washed with PBS under gently mixing for $5 \mathrm{~min}$ and then the supernatants were collected by centrifugation at $10,000 \mathrm{~g}$ for $3 \mathrm{~min} .10$ time-fold condensed sample solutions were prepared at the same time. $50 \mu \mathrm{L}$ of condensed samples were mixed with $100 \mu \mathrm{L}$ of anti-E. coli antibody functionalized MNP probe under gently shaking for $25 \mathrm{~min}$ at room temperature and then washed three times with PBS, followed by subjecting to dark-field microscopy for enumeration. In the meantime, the conventional colony enumeration method was employed as a comparison to evaluate the feasibility of our MNP-labeled dark-field counting strategy.

\section{Additional file}

\begin{abstract}
Additional file 1: Counting clones of dilute soup and rice samples in petri dishes. Dark-field images of real samples using the MNP-based counting method. Counting clones of dilute soup samples in petri dishes Counting clones of rice samples in petri dishes. 10 random views of darkfield images of MNP-E. coli from the ten-fold concentration dilute soup. Three repetitions were performed. 10 random views of dark-field images of MNP-E. coli from the ten-fold concentration rice. Three repetitions were performed. The counting numbers were marked on respective dark-field images. (DOCX 666 kb)
\end{abstract}

\section{Abbreviations}

CFU: Colony forming units; E. coli: Escherichia coli; ELISA: Enzyme linked immunosorbent assay; h: hour; LB: Luria Bertani; LOD: Limit of detection; min: minute; MNP: Magnetic nanoparticle; NPs: Nanoparticles; PBS: Phosphate buffered solution; PCR: Polymerase chain reaction; rpm: revolution per minute; SDS-PAGE: Sodium dodecyl sulfate-polyacrylamide gel electrophoresis;

TEM: Transmission electron microscopy

\section{Availability of data and material}

All data generated or analyzed during this study are included in this published article and the Additional file 1.

\section{Funding}

This work was supported by National Key R\&D Program of China (2016YFD0500800), the startup funds to X. Zhou provided by the Yangzhou University (137011016) and A Project Funded by the Priority Academic Program Development of Jiangsu Higher Education Institutions (Veterinary Medicine).

\section{Authors' contributions}

$X Z$ conceived the research work, guided the experiments and wrote the manuscript. HX performed most of the experiments, analyzed the experimental data and drafted the manuscript. FT Screened the pathogenic bacteria from chicken feces and participated in partial testing experiments. JD and CW critically revised the manuscript. All authors read and approved the final manuscript.

Ethics approval and consent to participate Not applicable.

Consent for publication Not applicable. 


\section{Competing interests}

The authors declare that they have no competing interests.

\section{Publisher's Note}

Springer Nature remains neutral with regard to jurisdictional claims in published maps and institutional affiliations.

\section{Author details}

${ }^{1}$ Institute of Comparative Medicine, Jiangsu Co-innovation Center for Prevention and Control of Important Animal Infectious Diseases and Zoonoses, Joint International Research Laboratory of Agriculture and Agri-Product Safety, the Ministry of Education of China, Yangzhou University, Yangzhou 225009, China. ${ }^{2}$ Key Laboratory of Animal Bacteriology, Ministry of Agriculture, College of veterinary medicine, Nanjing Agricultural University, Nanjing 210095, China. ${ }^{3}$ Department of Pathobiology, College of Veterinary Medicine, Auburn University, 268 Greene Hall, 1130 Wire Rd, Auburn, AL 36849-5519, USA.

Received: 5 February 2018 Accepted: 20 August 2018

\section{Published online: 03 September 2018}

\section{References}

1. Kaper JB, Nataro JP, Mobley HL. Pathogenic Escherichia coli. Nat Rev Microbiol. 2004;2(2):123-40

2. Chan KY, Ye WW, Zhang Y, Xiao LD, Leung PH, Li Y, Yang M. Ultrasensitive detection of E. Coli O157:H7 with biofunctional magnetic bead concentration via nanoporous membrane based electrochemical immunosensor. Biosens Bioelectron. 2013;41:532-7.

3. Roy D, Biswas B, Islam HM, Ahmed MS, Rasheduzzaman M, Sarower MG. Rapid identification of enterovirulent Escherichia coli strains using polymerase chain reaction from shrimp farms. Pak J Biol Sci. 2013;16(21):1260-9.

4. Miszczycha SD, Ganet S, Duniere L, Rozand C, Loukiadis E, Thevenot-Sergentet D. Novel real-time PCR method to detect Escherichia coli 0157:H7 in raw milk cheese and raw ground meat. J Food Prot. 2012;75(8):1373-81.

5. Son I, Binet R, Maounounen-Laasri A, Lin A, Hammack TS, Kase JA. Detection of five Shiga toxin-producing Escherichia coli genes with multiplex PCR. Food Microbiol. 2014:40:31-40

6. Wang F, Jiang L, Ge B. Loop-mediated isothermal amplification assays for detecting Shiga toxin-producing Escherichia coli in ground beef and human stools. J Clin Microbiol. 2012;50(1):91-7.

7. Uysal A, Durak Y. Pulsed-field gel electrophoresis typing, antibiotic resistance, and plasmid profiles of Escherichia coli strains isolated from foods. Can J Microbiol. 2012;58(11):1278-87.

8. Dowd SE, Ishizaki H. Microarray based comparison of two Escherichia coli 0157:H7 lineages. BMC Microbiol. 2006;6:30.

9. Jackson SA, Kotewicz ML, Patel IR, Lacher DW, Gangiredla J, Elkins CA. Rapid genomic-scale analysis of Escherichia coli O104:H4 by using high-resolution alternative methods to next-generation sequencing. Appl Environ Microbiol. 2012;78(5):1601-5.

10. Shan S, Liu D, Guo Q, Wu S, Chen R, Luo K, Hu L, Xiong Y, Lai W. Sensitive detection of Escherichia coli 0157:H7 based on cascade signal amplification in ELISA. J Dairy Sci. 2016:99(9):7025-32.

11. Yonekita T, Fujimura T, Morishita N, Matsumoto T, Morimatsu F. Simple, rapid, and reliable detection of Escherichia coli $\mathrm{O} 26$ using immunochromatography. J Food Prot. 2013;76(5):748-54.

12. Afonso AS, Perez-Lopez B, Faria RC, Mattoso LH, Hernandez-Herrero M, RoigSagues AX, Maltez-da Costa M, Merkoci A. Electrochemical detection of Salmonella using gold nanoparticles. Biosens Bioelectron. 2013;40(1):121-6.

13. Liebana S, Lermo A, Campoy S, Barbe J, Alegret S, Pividori MI. Magneto immunoseparation of pathogenic bacteria and electrochemical magneto genosensing of the double-tagged amplicon. Anal Chem. 2009;81(14):5812-20.

14. Baeumner AJ, Cohen RN, Miksic V, Min J. RNA biosensor for the rapid detection of viable Escherichia coli in drinking water. Biosens Bioelectron. 2003;18(4):405-13.

15. Sanvicens N, Pascual N, Fernandez-Arguelles MT, Adrian J, Costa-Fernandez JM, Sanchez-Baeza F, Sanz-Medel A, Marco MP. Quantum dot-based array for sensitive detection of Escherichia coli. Anal Bioanal Chem. 2011;399(8): 2755-62.

16. Hassan AR, de la Escosura-Muniz A, Merkoci A. Highly sensitive and rapid determination of Escherichia coli $0157: \mathrm{H7}$ in minced beef and water using electrocatalytic gold nanoparticle tags. Biosens Bioelectron. 2015;67:511-5.
17. Huang CJ, Dostalek J, Sessitsch A, Knoll W. Long-range surface plasmonenhanced fluorescence spectroscopy biosensor for ultrasensitive detection of E. Coli O157:H7. Anal Chem. 2011;83(3):674-7.

18. Kuhnert $P$, Boerlin $P$, Frey J. Target genes for virulence assessment of Escherichia coli isolates from water, food and the environment. FEMS Microbiol Rev. 2000;24(1):107-17.

19. Buchanan RL. Identifying and controlling emerging foodborne pathogens: research needs. Emerg Infect Dis. 1997;3(4):517-21.

20. Tokarskyy O, Marshall DL. Immunosensors for rapid detection of Escherichia coli 0157:H7 - perspectives for use in the meat processing industry. Food Microbiol. 2008:25(1):1-12

21. Lin YH, Chen SH, Chuang YC, Lu YC, Shen TY, Chang CA, Lin CS. Disposable amperometric immunosensing strips fabricated by au nanoparticlesmodified screen-printed carbon electrodes for the detection of foodborne pathogen Escherichia coli 0157:H7. Biosens Bioelectron. 2008:23(12):1832-7.

22. Li Y, Afrasiabi R, Fathi F, Wang N, Xiang C, Love R, She Z, Kraatz HB. Impedance based detection of pathogenic E. Coli O157:H7 using a ferrocene-antimicrobial peptide modified biosensor. Biosens Bioelectron. 2014:58:193-9.

\section{Ready to submit your research? Choose BMC and benefit from:}

- fast, convenient online submission

- thorough peer review by experienced researchers in your field

- rapid publication on acceptance

- support for research data, including large and complex data types

- gold Open Access which fosters wider collaboration and increased citations

- maximum visibility for your research: over $100 \mathrm{M}$ website views per year

At $\mathrm{BMC}$, research is always in progress.

Learn more biomedcentral.com/submissions 